\title{
Efficacy of EUS-guided FNB using a Franseen needle for tissue acquisition and microsatellite instability evaluation in unresectable pancreatic lesions
}

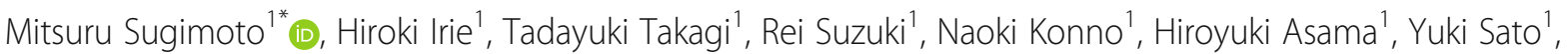
Jun Nakamura ${ }^{1,2}$, Mika Takasumi ${ }^{1}$, Minami Hashimoto ${ }^{1,2}$, Tsunetaka Kato', Ryoichiro Kobashi ${ }^{1}$, Yasuyuki Kobayashi ${ }^{3}$, Yuko Hashimoto ${ }^{3}$, Takuto Hikichi ${ }^{2}$ and Hiromasa Ohira'

\begin{abstract}
Background: The efficacy of immune checkpoint blockade in the treatment of microsatellite instability (MSI)-high tumors was recently reported. Therefore, the acquisition of histological specimens is desired in cases of unresectable solid pancreatic lesions (UR SPLS). This study investigated the efficacy of endoscopic ultrasoundguided fine-needle biopsy (EUS-FNB) using a Franseen needle for UR SPL tissue acquisition and MSI evaluation. Methods: A total of 195 SPL patients who underwent EUS-guided fine-needle aspiration (EUS-FNA) or EUS-FNB (EUS-FNAB) between January 2017 and March 2020 were enrolled in this study. Among them, 89 SPL patients (FNB: 28, FNA: 61) underwent EUS-FNAB using a 22-G needle (UR SPLs: 58, FNB: 22, FNA: 36) (UR SPLs after starting MSI evaluation: 23, FNB: 9, FNA: 14).
\end{abstract}

Results: The puncture number was significantly lower with FNB than with FNA (median (range): $3(2-5)$ vs $4(1-8), P<0.01$, UR SPLs: $3(2-5)$ vs $4(1-8), P=0.036$ ). Histological specimen acquisition was more commonly achieved with FNB than with FNA (92.9\% (26/28) vs 68.9\% (42/61), $P=0.015$, UR SPLs: 100\% (22/22) vs 72.2\% (26/36), $P<0.01)$. The histological specimen required for MSl evaluation was acquired more often with FNB than with FNA (88.9\% (8/9) vs $35.7 \%(5 / 14), P=0.03)$.

Conclusions: EUS-FNB using a Franseen needle is efficient for histological specimen acquisition and sampling the required amount of specimen for MSI evaluation in UR SPL patients.

Keywords: EUS-FNA, EUS-FNB, Unresectable pancreatic lesion, Microsatellite instability

\section{Background}

Endoscopic ultrasound-guided fine-needle aspiration (EUSFNA) is a safe and efficient procedure for diagnosing solid pancreatic lesions (SPLs), with a reported diagnostic sensitivity, specificity, and accuracy for SPL of 79-95.0\%, 75.0$100 \%$, and $78.0-96.0 \%$, respectively [1-6]. Furthermore, EUS-guided fine-needle biopsy (EUS-FNB) using a TruCut

\footnotetext{
* Correspondence: kita335@fmu.ac.jp

'Department of Gastroenterology, Fukushima Medical University, School of Medicine, 1 Hikarigaoka, Fukushima 960-1295, Japan

Full list of author information is available at the end of the article
}

needle improves the diagnostic yield and tissue acquisition and reduces the number of needle passes [7-9].

Microsatellite instability (MSI) is known as a predictive biomarker for the therapeutic effect of immune checkpoint blockade. Pembrolizumab has been proposed as a second-line treatment for any MSI-high cancer patients $[10,11]$. In the guidelines for pancreatic cancer published by the Japan Pancreatic Society, it is stated that pembrolizumab is a second-line treatment for locally advanced or metastatic pancreatic cancer [12]. However, sufficient tissue preparation is needed to investigate MSI.

(c) The Author(s). 2020 Open Access This article is licensed under a Creative Commons Attribution 4.0 International License, which permits use, sharing, adaptation, distribution and reproduction in any medium or format, as long as you give appropriate credit to the original author(s) and the source, provide a link to the Creative Commons licence, and indicate if changes were made. The images or other third party material in this article are included in the article's Creative Commons licence, unless indicated otherwise in a credit line to the material. If material is not included in the article's Creative Commons licence and your intended use is not permitted by statutory regulation or exceeds the permitted use, you will need to obtain permission directly from the copyright holder. To view a copy of this licence, visit http://creativecommons.org/licenses/by/4.0/ The Creative Commons Public Domain Dedication waiver (http://creativecommons.org/publicdomain/zero/1.0/) applies to the data made available in this article, unless otherwise stated in a credit line to the data. 
Recently, EUS-FNB using a Franseen needle has been reported to be more useful for tissue acquisition in cases of SPL [13-15]. However, tissue acquisition is not absolutely required for patients with resectable (R) SPL. Because tissue acquisition is important for MSI evaluation, tissue acquisition by EUS-FNB is required for patients with unresectable (UR) SPL. It remains unknown whether EUS-FNB using a Franseen needle is effective for tissue sampling and MSI evaluation only in UR SPL patients. Therefore, we aimed to reveal the efficacy of EUS-FNB using a Franseen needle in UR SPL patients.

\section{Methods}

\section{Study design and ethics}

This study is the retrospective study. Patients were not required to give informed consent because this study used anonymous clinical data obtained after each patient had agreed to medical activities by written consent. For full disclosure, the details of this study are published on the home page of Fukushima Medical University.

\section{Patients}

A total of 195 SPL patients who underwent EUS-FNA or EUS-FNB (EUS-FNAB) between January 2017 and March 2020 were enrolled in this study (Fig. 1). Among these patients, 89 SPL patients underwent EUS-FNAB using a 22-G needle (FNB: 28 patients, FNA: 61 patients). The SPLs of 58 patients were UR (FNB: 22 patients, FNA 36 patients).

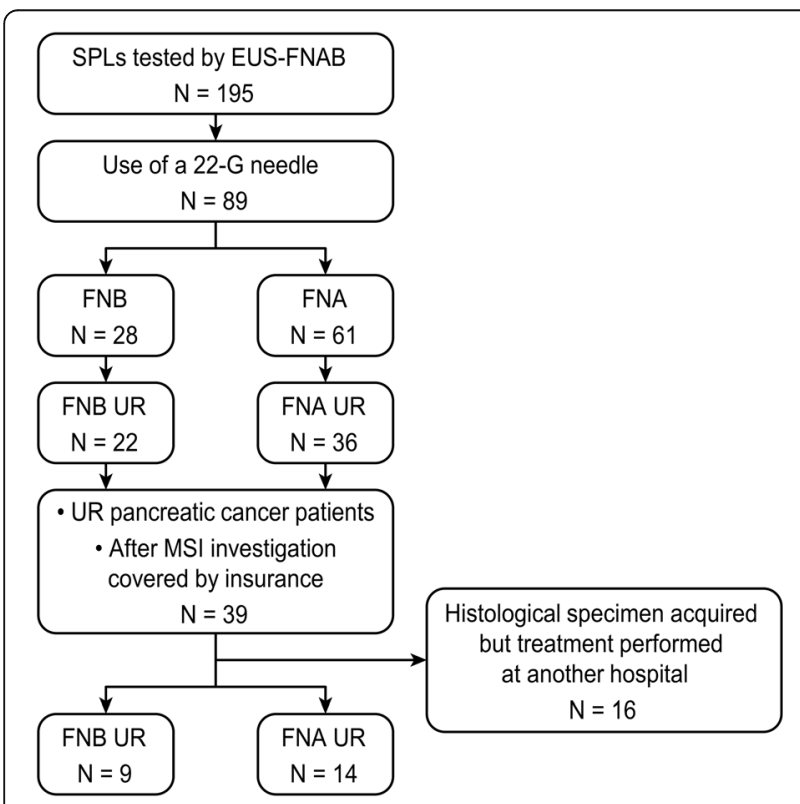

Fig. 1 Flow chart of patient grouping in this study. SPL, solid pancreatic lesion; EUS-FNAB, endoscopic ultrasound-guided fine-needle aspiration biopsy; UR, unresectable; MSI, microsatellite instability
Thirty-nine pancreatic cancer patients underwent EUSFNAB after the MSI evaluation was covered by insurance in Japan. Among these patients, 16 patients had undergone the process of histological specimen acquisition but had received treatment at another hospital. Among the other 23 patients, EUS-FNB was performed in 9 patients, and EUS-FNA was performed in 14 patients.

\section{EUS-FNAB procedures}

The echoendoscope was gently inserted into the patient while in the left lateral decubitus position after sufficient sedation by the intravenous administration of midazolam. After the SPL was visualized on the monitor, the lack of blood flow on the aspiration line was confirmed using Doppler mode. Then, the needle was advanced to the SPL, and the stylet was removed. The needle was passed back and forth 20 times in the SPL while applying suction using a 20 - or $10-\mathrm{ml}$ syringe. The fanning method was utilized as much as possible for puncture [16]. Aspiration was repeated until sufficient material was confirmed by rapid onsite cytology (ROSE) [17, 18].

The following ultrasonography equipment and echoendoscopes were used in this study: EU-ME-1, EU-ME-2, GFUC240AL-5, or GF-UCT260 (Olympus Medical Systems, Tokyo, Japan). The selection of the FNAB needle was as follows. For patients with an R SPL or a small SPL, a conventional FNA needle tended to be used because of its good penetration ability. Otherwise, the chosen needle was randomly selected by each endoscopist. The Franseen needle used for EUS-FNB in this study was an Acquire 22-G needle (Boston Scientific, MA, USA) (Fig. 2). The cutting surface of the Franseen needle (on the bottom of Fig. 2) is larger than that of the conventional aspiration needle (on the top of Fig. 2). The needles used for EUS-FNA in this study were an Expect 22-G needle (Boston Scientific, MA, USA), an EZ Shot 3 plus 22-G needle (Olympus Medical Systems), and an EchoTip 22-G needle (Cook Medical, Inc., NC, USA).

All procedures were performed by pancreaticobiliary specialists who had performed more than 200 EUSFNAB procedures or beginners under the guidance of pancreaticobiliary specialists. The puncture needles were randomly chosen by each endoscopist.

\section{Examination items}

The patient characteristics (age, sex), SPL data (tumor size, tumor location, resectability), and procedural characteristics (puncture route, puncture number, histology, adverse events) were compared between patients who underwent EUS-FNB and those who underwent EUS-FNA. In the UR SPL patients, similar comparisons were performed. The tumor size was the maximum diameter measured by EUS or computed tomography (CT). UR SPLs were determined by the following characteristics: 1 . contacts/invades the superior mesenteric vein or portal vein by more than 180 


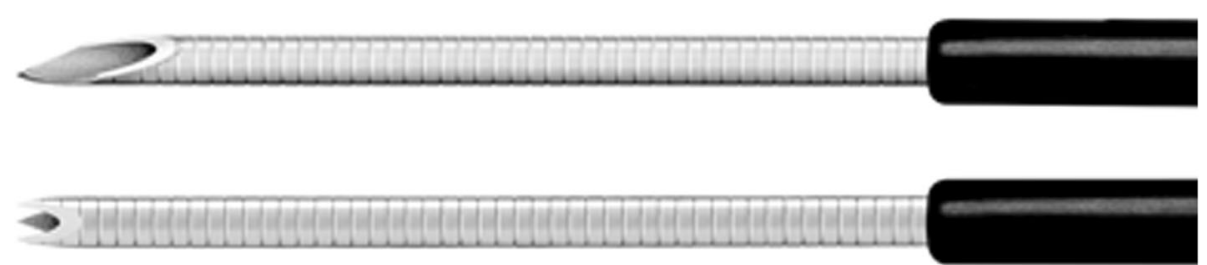

Fig. 2 The Franseen needle used for EUS-FNB (image provided by Boston Scientific Japan). The needle on the top is a conventional EUS-FNA needle. The cutting surface of the conventional FNA needle is in a lancet shape. The needle on the bottom is an FNB needle. The cutting surface is larger by adopting the Franseen design

degrees with a range of contact/invasion exceeding the inferior duodenal angle; 2 . contacts/invades the superior mesenteric artery or celiac artery by more than 180 degrees; 3 . contacts/invades the common hepatic artery with a range of contact/invasion extending to the proper hepatic artery or celiac artery; 4. contacts/invades the aorta; and 5 . distant metastases $[19,20]$. R SPLs were finally diagnosed by surgery. On the other hand, UR SPLs were diagnosed by cytology or histology on EUS-FNAB. Malignancy was defined by class IV or V cytology.

In some UR SPL patients who underwent EUSFNAB after the MSI evaluation was covered by insurance, the possibility of performing the MSI evaluation using the histological specimens was compared between EUS-FNB and EUS-FNA.

\section{Requirements for histology and MSI evaluation}

A histological diagnosis was attempted to be made using all the specimens submitted to department of pathology. To diagnose malignancy, the specimen must include tumor tissue that is not crushed or degenerated. If tumor tissues are fragmented or crushed, the diagnosis of malignancy become difficult. Furthermore, if a specimen contains inflammatory components, it become difficult to distinguish whether atypical cells are tumoral or reactive to inflammation.

To extract DNA for MSI evaluation, more than 2000 tumor cells are necessary. Additionally, more than 50\% tumor cell content is needed. More than five unstained slide specimens of SPLs had to be prepared for the investigation of MSI. An MSI detection kit (FALCO HOLDINGS Co., Ltd., Kyoto, Japan) was used to measure MSI according to five mononucleotide markers (BAT-25, BAT-26, NR-21, NR-24, and MONO-27). When more than two markers were MSI positive, the tumor was defined as MSI-high.

\section{Statistical analyses}

Continuous variables that did not conform to a normal distribution and ordinal variables were compared by the Mann-Whitney $U$ test. Nominal variables were compared by Fisher's exact test. A $P$ value $<0.05$ was considered significantly different. All statistical analyses were performed with EzR (Saitama Medical Centre, Jichi Medical University, Saitama, Japan) [21].

Table 1 Patient and SPL characteristics and outcomes of EUS-FNAB

\begin{tabular}{|c|c|c|c|}
\hline & FNB $(N=28)$ & FNA $(N=61)$ & $P$ value \\
\hline Age, $y$, median (range) & $68(49-91)$ & $70(38-85)$ & 0.33 \\
\hline Sex, male/female & $18 / 10$ & $30 / 31$ & 0.25 \\
\hline Final diagnosis & & & 0.09 \\
\hline Pancreatic cancer & 28 & 54 & \\
\hline Pancreatic neuroendocrine tumor & & 7 & \\
\hline SPL size, mm, median (range) & $25(15-50)$ & $27(7-82)$ & 0.81 \\
\hline SPL location, head/body or tail & $11 / 17$ & $27 / 34$ & 0.82 \\
\hline Lesion resectability, R/UR & $6 / 22$ & $25 / 36$ & 0.09 \\
\hline Puncture route, gastric/duodenal & $20 / 8$ & $42 / 29$ & 1.0 \\
\hline Puncture number, median (range) & $3(2-5)$ & $4(1-8)$ & $<0.01$ \\
\hline Histological specimen, n (\%) & $26(92.9)$ & $42(68.9)$ & 0.015 \\
\hline Adverse events, n (\%) & $0(0)$ & $2(3.3)$ & 1.0 \\
\hline Acute pancreatitis, $n$ & & 1 & \\
\hline Bleeding, $n$ & & 1 & \\
\hline
\end{tabular}

SPL Solid pancreatic lesion, $R$ Resectable, UR Unresectable 


\section{Results}

\section{FNAB with a 22-G needle in SPL patients}

The patient characteristics, final diagnosis, tumor size, tumor location, resectability, puncture route, and adverse events were not significantly different between patients who underwent FNB and those who underwent FNA (Table 1). Both adverse events after FNA improved with conservative

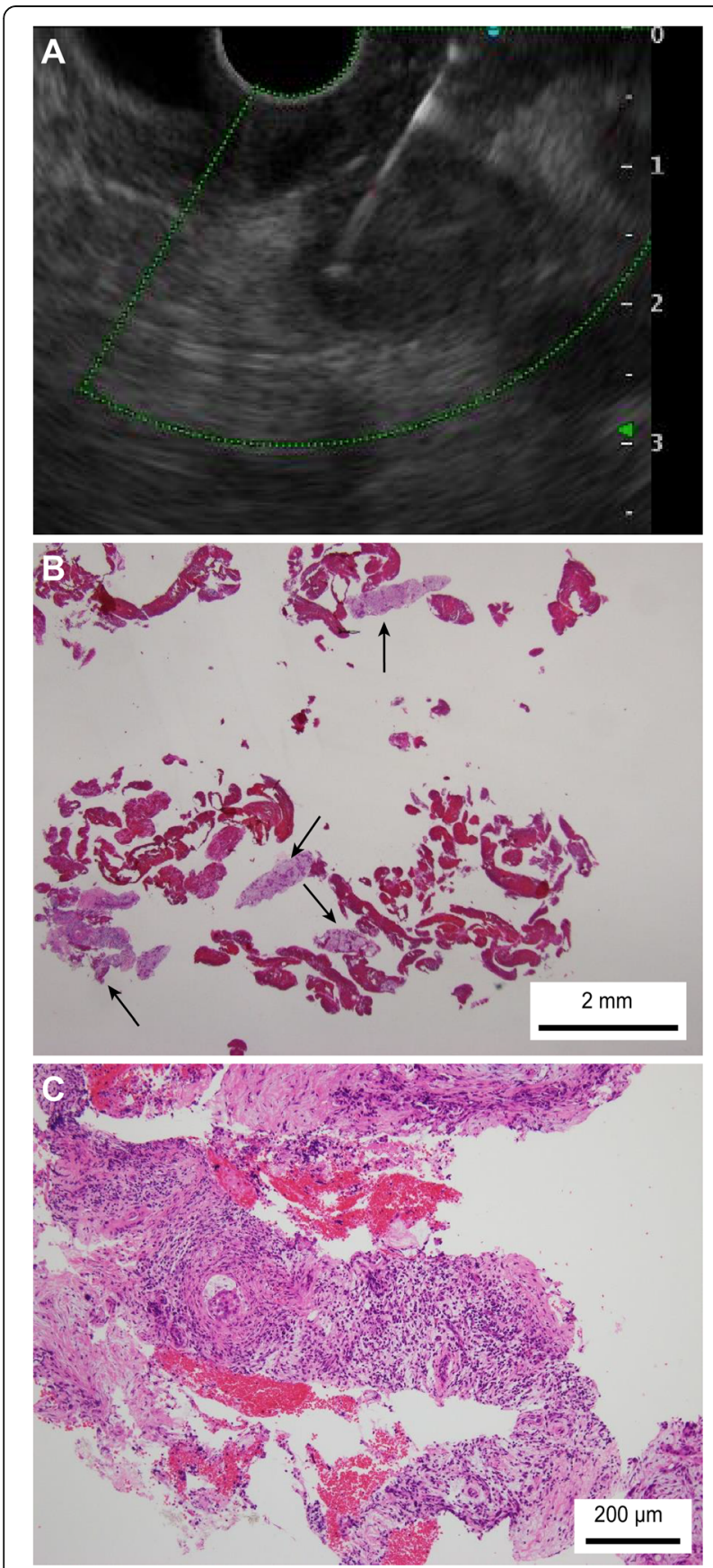

Fig. 3 EUS-FNB specimen obtained using a Franseen needle. a A 15$\mathrm{mm}$ pancreatic cancer lesion was punctured with a 22-G Franseen needle. b Some large tissue preparations were confirmed. (c) A sufficient number of tumor cells were observed treatment. The puncture number was significantly lower with FNB than with FNA (median (range); 3 (2-5) vs 4 (1$8), P$ value $<0.01)$. Furthermore, histological specimens were obtained significantly more often by FNB than by FNA $(92.9 \%(26 / 28)$ vs $68.9 \%(42 / 61), P$ value $=0.015)$. A tissue specimen obtained by EUS-FNB is shown in Fig. 3. A tissue specimen obtained by EUS-FNA is shown in Fig. 4.

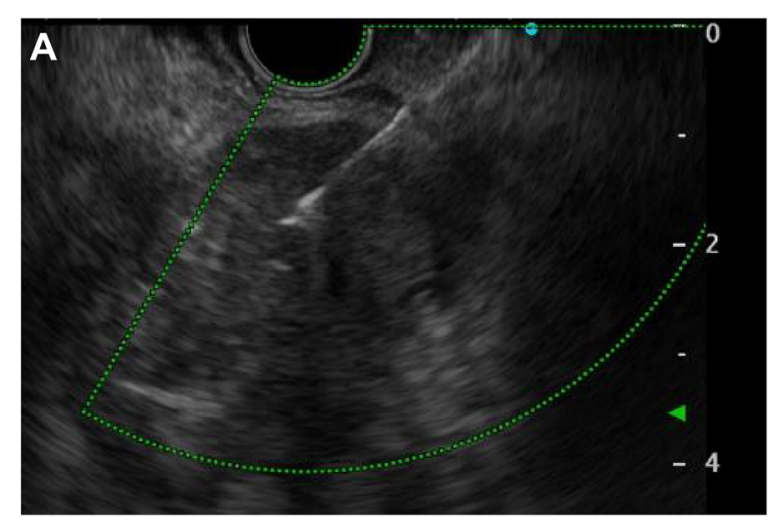

B
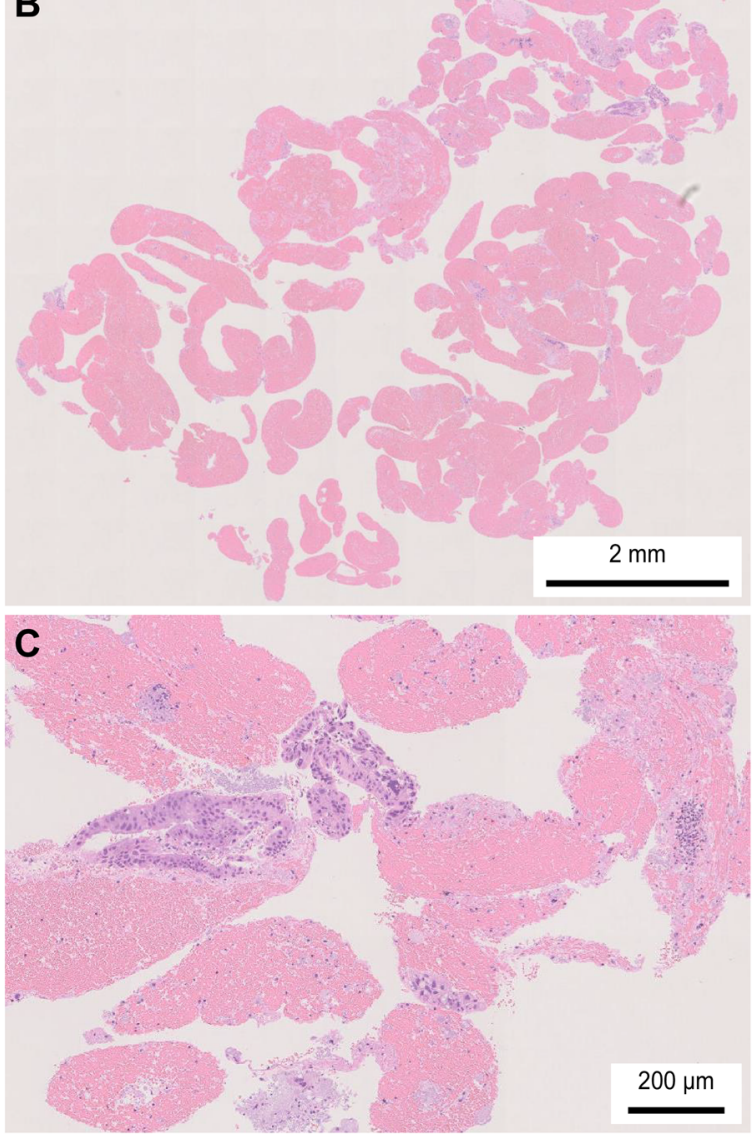

Fig. 4 EUS-FNA specimen obtained using a lancet-shaped needle. a The visibility of the 22-G lancet-shape needle was not much different from that of the Franseen needle. $\mathbf{b}$ In a low-power field, evident large tissue preparations were not observed. $\mathbf{c}$ In a high-power field, tumor cells were confirmed; however, there were not as many as in Fig. 3c 
Table 2 Patient and SPL characteristics and outcomes of EUS-FNAB in UR SPL patients

\begin{tabular}{|c|c|c|c|}
\hline & FNB, UR $(N=22)$ & FNA, UR $(N=36)$ & $P$ value \\
\hline Age, y, median (range) & $68(49-91)$ & $70(38-84)$ & 0.79 \\
\hline Sex, male/female & $15 / 7$ & $21 / 15$ & 0.58 \\
\hline Final diagnosis & & & 0.52 \\
\hline Pancreatic cancer & 22 & 34 & \\
\hline Pancreatic neuroendocrine tumor & & 2 & \\
\hline SPL size, mm, median (range) & $30(15-50)$ & $30(10-82)$ & 0.70 \\
\hline SPL location, head/body or tail & $8 / 14$ & $14 / 22$ & 1.0 \\
\hline Puncture route, gastric/duodenal & $16 / 6$ & $26 / 10$ & 1.0 \\
\hline Puncture number, median (range) & $3(2-5)$ & $4(1-8)$ & 0.036 \\
\hline Histological specimen, n (\%) & $22(100)$ & $26(72.2)$ & $<0.01$ \\
\hline Adverse events, $n(\%)$ & $0(0)$ & $1(2.8)$ & 1.0 \\
\hline Bleeding, $\mathrm{n}$ & & 1 & \\
\hline
\end{tabular}

SPL Solid pancreatic lesion, UR unresectable

\section{FNAB with a 22-G needle in UR SPL patients}

The patient characteristics, final diagnosis, tumor size, tumor location, puncture route, and adverse events were not significantly different between patients who underwent FNB and those who underwent FNA (Table 2). The puncture number was significantly lower with FNB than with FNA (median (range); $3(2-5)$ vs $4(1-8), P$ value $=0.036$ ). Futhermore, histological specimens were obtained significantly more often by FNB than by FNA $(100 \%(22 / 22)$ vs $72.2 \%(26 / 36), P$ value $<0.01)$.

\section{MSI of pancreatic cancer specimens obtained by EUS- FNAB}

The size of the SPL, puncture route, and number of punctures were not significantly different between patients who underwent FNB and those who underwent FNA (Table 3). The MSI evaluation was achieved significantly more often with FNB than with FNA $(88.9 \%(8 / 9)$ vs $35.7 \%(5 / 14), P$ value $=0.03)$. MSI-high tumors were not observed in any of the patients.

\section{Discussion}

In this manuscript, we investigated the efficacy of EUSFNB using a Franseen needle for UR SPL patients. As a result, histological specimens were collected significantly more often with EUS-FNB than with EUS-FNA.
Furthermore, EUS-FNB required fewer punctures than EUS-FNA for diagnosing UR SPLs, and the MSI evaluation was achieved more often by EUS-FNB than by EUSFNA.

Several factors that may affect the diagnostic value of EUSFNA have been reported. Regarding the relationship between EUS-FNA and tumor size, there are multiple points of view [5, 22]. Haba et al. [22] reported that in cases of smaller lesions, the diagnostic value of EUS-FNA is reduced. On the other hand, Uehara et al. [5] found that the tumor size does not influence the diagnostic value of EUS-FNA. It is true that EUS-FNA is difficult for small lesions; however, it is not true that the diagnostic value of EUS-FNA increases with increasing tumor size because the presence of necrosis could affect the accuracy of EUS-FNA. Contrast-enhanced EUSFNA was reported to avoid puncture of necrotic areas [23-25]. Necrotic areas can be observed more clearly in larger SPLs than in small SPLs, and it is difficult to identify necrotic areas using only B-mode imaging. In this study, the UR SPLs were larger than the R SPLs (median (range): $30(10-82) \mathrm{mm}$ vs $20(7-40) \mathrm{mm}, P$ value $<0.01)$. Although the evaluation of necrotic areas on EUS is difficult, the superiority of EUS-FNB using a Franseen needle over EUS-FNA was proven in SPLs and UR SPLs.

In past reports, the frequency of MSI-high tumors was $0-29 \%$ in pancreatic cancer [26-31]. However,

Table 3 Comparison of MSI

\begin{tabular}{llll}
\hline & FNB, UR $(\boldsymbol{N}=\mathbf{9})$ & FNA, UR $(\boldsymbol{N}=\mathbf{1 4})$ & $\boldsymbol{P}$ value \\
\hline SPL size, mm, median (range) & $25(15-50)$ & $30(15-82)$ & 0.63 \\
Puncture route, gastric/duodenal & $7 / 2$ & $9 / 5$ & 0.66 \\
Puncture number, median (range) & $3(2-5)$ & $4(1-7)$ & 0.26 \\
Possibility of MSI evaluation, n (\%) & $8(88.9)$ & $5(35.7)$ & 0.03 \\
MSI-high tumors, n & 0 & 0 & \\
\hline
\end{tabular}


frequencies of MSI-high tumors of more than 10\% were reported in small studies. In a study with a large number of patients $(n=3954)$ [28], MSI-high pancreatic cancer was found in very few patients $(0.5 \%)$. In a study that targeted 12,019 patients with 32 types of cancer, the rate of MSI-high tumors was less than $2 \%$ among those with pancreatic cancer [32]. Therefore, it is reasonable that MSIhigh tumors were not observed in this study.

What about the difference in the measurement method? In recent reports using next-generation sequencing, the frequency of MSI-high tumors among patients with pancreatic cancer was $0.5 \%$ or less than $2 \%$ [28, 32]. On the other hand, Yamamoto et al. [30] reported that $13 \%$ of pancreatic cancer patients showed MSI-high tumors according to PCR and that the results were satisfactory. In the report written by Yamamoto et al. [30], the Bethesda panel was used. In this study, the Promega panel was used. In the report written by Murphy et al. [33], the Promega panel was superior to the Bethesda panel. Therefore, there should be no problem with the MSI measurement method in this study.

As described above, the frequency of MSI-high tumors is low in pancreatic cancer. However, dramatic efficacy of pembrolizumab has been reported in MSI-high pancreatic cancer [31]. Thus, EUS-FNB using a Franseen needle should be performed to collect sufficient specimens for MSI evaluation. The shape of the needle tip could contribute to the superiority of FNB for tissue acquisition (Fig. 2). There are three cutting surfaces on a Franseen needle, whereas there is only one lancetshaped cutting surface on a conventional FNA needle tip. This difference in the number of cutting surfaces may produce a difference in the cutting area.

Based on the above, we describe appropriate cases in which EUS-FNB should be performed. For diagnosing $\mathrm{R}$ SPLs, cytology alone is enough. Therefore, EUS-FNA is also sufficient for diagnosing these cases. However, for diagnosing UR SPLs, EUS-FNB should be performed to obtain a sufficient specimen for MSI investigation. Furthermore, EUS-FNB should be performed in patients whose disease requires many specimens for diagnosis, such as those with autoimmune pancreatitis [34, 35].

There are several limitations to this study. First, this study was a small retrospective study performed at a single institution. The types of puncture needles used were not randomly assigned. Therefore, selection bias could exist in this study. In the future, it is desirable for a multicenter prospective study to prove the argument of this study. Second, the types of SPLs were not unified. However, only UR pancreatic cancer patients were involved in the MSI comparison. Therefore, there was no influence of the SPL type in the MSI comparison between FNB and FNA. Third, the weight and volume of cells were not measured. Instead, the suitability of histological specimen sampling was compared between the two groups. The histological evaluation was performed by experienced pathologists.

\section{Conclusions}

EUS-FNB using a Franseen needle could be efficient for histological specimen acquisition and MSI evaluation in UR SPL patients.

\section{Abbreviations}

MSI: Microsatellite instability; UR: Unresectable; SPL: Solid pancreatic lesion; EUS-FNB: EUS-guided fine needle biopsy; EUS-FNA: EUS-guided fine needle aspiration; EUS-FNAB: EUS-FNA or EUS-FNB; R: Resectable; ROSE: Rapid onsite cytology; CT: Computed tomography

\section{Acknowledgements}

We thank all the staff at the Department of Gastroenterology of Fukushima Medical University, the Department of Endoscopy of Fukushima Medical University Hospital, and the gastroenterology ward of Fukushima Medical University Hospital. We also thank American Journal Experts for providing English language editing.

\section{Authors' contributions}

MS wrote the paper and designed and performed the research and laboratory analyses; $\mathrm{HI}$ wrote the paper and designed and oversaw the research; TT, RS, NK, HA, TH, JN, MT, YS, MH, TK and RK provided clinical advice; $\mathrm{TH}$ supervised the report; $Y K$ and $Y H$ performed the pathological diagnoses; and $\mathrm{HO}$ supervised the report and the writing of the paper. All authors have read and approved the final manuscript.

\section{Funding}

Not applicable.

\section{Availability of data and materials}

The datasets generated and/or analyzed during the current study are available from the corresponding author upon reasonable request.

\section{Ethics approval and consent to participate}

The study protocol was reviewed and approved by the Institutional Review Board of Fukushima Medical University (Number 2399). This study is the retrospective study. Patients were not required to give informed consent because this study used anonymous clinical data obtained after each patient had agreed to medical activities by written consent. For full disclosure, the details of this study are published on the home page of Fukushima Medical University.

\section{Consent for publication}

Not applicable.

\section{Competing interests}

The authors declare that they have no competing interests.

\section{Author details}

'Department of Gastroenterology, Fukushima Medical University, School of Medicine, 1 Hikarigaoka, Fukushima 960-1295, Japan. ${ }^{2}$ Department of Endoscopy, Fukushima Medical University Hospital, Fukushima, Japan. ${ }^{3}$ Department of Diagnostic Pathology, Fukushima Medical University, School of Medicine, Fukushima, Japan.

Received: 23 July 2020 Accepted: 29 October 2020

Published online: 11 November 2020

\section{References}

1. Williams DB, Sahai AV, Aabakken L, Penman ID, van Velse A, Webb J, et al. Endoscopic ultrasound guided fine needle aspiration biopsy: a large single Centre experience. Gut. 1999;44:720-6. 
2. Eloubeidi MA, Jhala D, Chhieng DC, Chen VK, Eltoum I, Vickers S, et al. Yield of endoscopic ultrasound-guided fine-needle aspiration biopsy in patients with suspected pancreatic carcinoma. Cancer. 2003;99:285-92.

3. Ryozawa S, Kitoh H, Gondo T, Urayama N, Yamashita H, Ozawa H, et al. Usefulness of endoscopic ultrasound-guided fine-needle aspiration biopsy for the diagnosis of pancreatic cancer. J Gastroenterol. 2005;40:907-11.

4. Yoshinaga S, Suzuki H, Oda I, Saito Y. Role of endoscopic ultrasound-guided fine needle aspiration (EUS-FNA) for diagnosis of solid pancreatic masses. Dig Endosc. 2011;23(Suppl 1):29-33.

5. Uehara H, Ikezawa K, Kawada N, Fukutake N, Katayama K, Takakura R, et al. Diagnostic accuracy of endoscopic ultrasound-guided fine needle aspiration for suspected pancreatic malignancy in relation to the size of lesions. J Gastroenterol Hepatol. 2011;26:1256-61.

6. Mohammad Alizadeh AH, Shahrokh S, Hadizadeh M, Padashi M, Zali MR. Diagnostic potency of EUS-guided FNA for the evaluation of pancreatic mass lesions. Endosc Ultrasound. 2016;5:30-4.

7. Varadarajulu S, Fraig M, Schmulewitz N, Roberts S, Wildi S, Hawes RH, et al. Comparison of EUS-guided 19-gauge Trucut needle biopsy with EUSguided fine-needle aspiration. Endoscopy. 2004;36:397-401.

8. Dwyer J, Pantanowitz L, Ohori NP, Pai RK, Vrbin C, Brand RE, et al. Endoscopic ultrasound-guided FNA and ProCore biopsy in sampling pancreatic and intra-abdominal masses. Cancer Cytopathol. 2016;124:11021.

9. Lee BS, Cho CM, Jung MK, Jang JS, Bae HI. Comparison of histologic Core portions acquired from a Core biopsy needle and a conventional needle in solid mass lesions: a prospective randomized trial. Gut Liver. 2017;11:559-66.

10. Chung HC, Ros W, Delord JP, Perets R, Italiano A, Shapira-Frommer R, et al. Efficacy and safety of Pembrolizumab in previously treated advanced cervical Cancer: results from the phase II KEYNOTE-158 study. J Clin Oncol. 2019:37:1470-8

11. Le DT, Uram JN, Wang H, Bartlett BR, Kemberling H, Eyring AD, et al. PD-1 blockade in tumors with mismatch-repair deficiency. N Engl J Med. 2015; 372:2509-20.

12. Okusaka T, Furuse J. Recent advances in chemotherapy for pancreatic cancer: evidence from Japan and recommendations in guidelines. J Gastroenterol. 2020;55:369-82.

13. Alkhateeb K, Lee BB, Alatassi H, Sanders MA, Omer EM, McClave SA, et al. Comparison between two types of needles for endoscopic ultrasound (EUS)-guided fine aspiration biopsy of pancreatic and upper gastrointestinal masses. Diagn Cytopathol. 2020;48:197-202.

14. El H II, Wu H, Reuss S, Randolph M, Harris A, Gromski MA, et al. Prospective assessment of the performance of a new fine needle biopsy device for EUSguided sampling of solid lesions. Clin Endosc. 2018;51:576-83.

15. Mukai S, Itoi T, Yamaguchi H, Sofuni A, Tsuchiya T, Tanaka R, et al. A retrospective histological comparison of EUS-guided fine-needle biopsy using a novel franseen needle and a conventional end-cut type needle. Endosc Ultrasound. 2019;8:50-7.

16. Bang JY, Magee SH, Ramesh J, Trevino JM, Varadarajulu S. Randomized tria comparing fanning with standard technique for endoscopic ultrasoundguided fine-needle aspiration of solid pancreatic mass lesions. Endoscopy. 2013:45:445-50

17. Hikichi T, Irisawa A, Bhutani MS, Takagi T, Shibukawa G, Yamamoto G, et al. Endoscopic ultrasound-guided fine-needle aspiration of solid pancreatic masses with rapid on-site cytological evaluation by endosonographers without attendance of cytopathologists. J Gastroenterol. 2009;44:322-8.

18. Dumonceau JM, Koessler T, van Hooft JE, Fockens P. Endoscopic ultrasonography-guided fine needle aspiration: relatively low sensitivity in the endosonographer population. World I Gastroenterol. 2012;18:2357-63.

19. Varadhachary GR, Tamm EP, Abbruzzese JL, Xiong HQ, Crane CH, Wang H, et al. Borderline resectable pancreatic cancer: definitions, management, and role of preoperative therapy. Ann Surg Oncol. 2006;13:1035-46.

20. Japan Pancreas Society. General rules for the study of pancreatic cancer. Tokyo: Japan Pancreas Society; 2016.

21. Kanda Y. Investigation of the freely available easy-to-use software 'EZR' for medical statistics. Bone Marrow Transplant. 2013;48:452-8.

22. Haba S, Yamao K, Bhatia V, Mizuno N, Hara K, Hijioka S, et al. Diagnostic ability and factors affecting accuracy of endoscopic ultrasound-guided fine needle aspiration for pancreatic solid lesions: Japanese large single center experience. J Gastroenterol. 2013;48:973-81.

23. Seicean A, Badea R, Moldovan-Pop A, Vultur S, Botan EC, Zaharie T, et al. Harmonic contrast-enhanced endoscopic ultrasonography for the guidance of fine-needle aspiration in solid pancreatic masses. Ultraschall Med. 2017; 38:174-82.

24. Sugimoto M, Takagi T, Hikichi T, Suzuki R, Watanabe K, Nakamura J, et al. Conventional versus contrast-enhanced harmonic endoscopic ultrasonography-guided fine-needle aspiration for diagnosis of solid pancreatic lesions: a prospective randomized trial. Pancreatology. 2015;15: $538-41$.

25. Hou X, Jin Z, Xu C, Zhang M, Zhu J, Jiang F, et al. Contrast-enhanced harmonic endoscopic ultrasound-guided fine-needle aspiration in the diagnosis of solid pancreatic lesions: a retrospective study. Plos One. 2015; 10:e0121236.

26. Goggins M, Offerhaus GJ, Hilgers W, Griffin CA, Shekher M, Tang D, et al. Pancreatic adenocarcinomas with DNA replication errors (RER+) are associated with wild-type K-ras and characteristic histopathology. Poor differentiation, a syncytial growth pattern, and pushing borders suggest RER+. Am J Pathol. 1998;152:1501-7.

27. Ouyang H, Furukawa T, Abe T, Kato Y, Horii A. The BAX gene, the promoter of apoptosis, is mutated in genetically unstable cancers of the colorectum, stomach, and endometrium. Clin Cancer Res. 1998:4:1071-4.

28. Singhi AD, George B, Greenbowe JR, Chung J, Suh J, Maitra A, et al. Realtime targeted genome profile analysis of pancreatic ductal adenocarcinomas identifies genetic alterations that might be targeted with existing drugs or used as biomarkers. Gastroenterology. 2019;156:2242-53. e4.

29. Venkatasubbarao K, Ahmed MM, Swiderski C, Harp C, Lee EY, McGrath P, et al. Novel mutations in the polyadenine tract of the transforming growth factor beta type II receptor gene are found in a subpopulation of human pancreatic adenocarcinomas. Genes Chromosomes Cancer. 1998;22:138-44.

30. Yamamoto H, Itoh F, Nakamura H, Fukushima H, Sasaki S, Perucho M, et al. Genetic and clinical features of human pancreatic ductal adenocarcinomas with widespread microsatellite instability. Cancer Res. 2001;61:3139-44.

31. Kamatham S, Shahjehan F, Kasi PM. Circulating tumor DNA-based detection of microsatellite instability and response to immunotherapy in pancreatic Cancer. Front Pharmacol. 2020;11:23.

32. Le DT, Durham JN, Smith KN, Wang H, Bartlett BR, Aulakh LK, et al. Mismatch repair deficiency predicts response of solid tumors to PD-1 blockade. Science. 2017;357:409-13.

33. Murphy KM, Zhang S, Geiger T, Hafez MJ, Bacher J, Berg KD, et al. Comparison of the microsatellite instability analysis system and the Bethesda panel for the determination of microsatellite instability in colorectal cancers. J Mol Diagn. 2006;8:305-11.

34. Ishikawa T, Kawashima H, Ohno E, Suhara H, Hayashi D, Hiramatsu T, et al. Usefulness of endoscopic ultrasound-guided fine-needle biopsy for the diagnosis of autoimmune pancreatitis using a 22-gauge Franseen needle: a prospective multicenter study. Endoscopy. 2020;52:978-85.

35. Kurita A, Yasukawa S, Zen Y, Yoshimura K, Ogura T, Ozawa E, et al. Comparison of a 22-gauge Franseen-tip needle with a 20-gauge forwardbevel needle for the diagnosis of type 1 autoimmune pancreatitis: a prospective, randomized, controlled, multicenter study (COMPAS study). Gastrointest Endosc. 2020;91:373-81 e2.

\section{Publisher's Note}

Springer Nature remains neutral with regard to jurisdictional claims in published maps and institutional affiliations.

Ready to submit your research? Choose BMC and benefit from:

- fast, convenient online submission

- thorough peer review by experienced researchers in your field

- rapid publication on acceptance

- support for research data, including large and complex data types

- gold Open Access which fosters wider collaboration and increased citations

- maximum visibility for your research: over $100 \mathrm{M}$ website views per year

At BMC, research is always in progress.

Learn more biomedcentral.com/submission 